\title{
PENGEMBANGAN GAME EDUKASI TENTANG BUDAYA NUSANTARA "TANARA" MENGGUNAKAN UNITY 3D BERBASIS ANDROID
}

\author{
Indah Rohmawati ${ }^{1}$, Sudargo $^{2}$, Ika Menarianti ${ }^{3}$ \\ ${ }^{1,3}$ Prodi Pendidikan Teknologi Informasi, Fakultas Pendidikan Matematika Ilmu Pengetahuan Alam dan Teknologi \\ Informasi, Universitas PGRI Semarang \\ 2 Prodi Pendidikan Matematika, Fakultas Pendidikan Matematika Ilmu Pengetahuan Alam dan Teknologi \\ Informasi, Universitas PGRI Semarang
}

Article Info:

Dikirim: 20 September 2019

Direvisi: 16 Desember 2019

Diterima: 31 Desember 2019

Tersedia Online: 31 Desember 2019

Penulis Korespondensi: Indah Rohmawati Universitas PGRI Semarang, Semarang, Indonesia Email: Rindah25@gmail.com

\begin{abstract}
Abstrak: Aplikasi game edukasi tentang budaya nusantara "TANARA" ini dibuat sebagai alternatif media belajar untuk mengenal kebudayaan yang ada di Indonesia bagi anak - anak khususnya siswa sekolah. Metodologi yang digunakan dalam penelitian ini adalah Multimedia Development Life Cycle (MDLC) yang bersumber dari Luther yang dimodifikasi oleh Sutopo, yang terdiri dari enam tahap yaitu konsep, desain, pengumpulan materi, pembuatan, pengujian dan distribusi. Aplikasi game edukasi "TANARA" dirancang dan dibuat menggunakan software corel draw untuk desain dan unity untuk pemograman hasil akhir aplikasi berbasis android dijalankan secara offline. Pengujian aplikasi yaitu dengan validasi kepada ahli media dan ahli materi dalam bentuk angket. Uji validasi ahli media dilakukan dengan menguji aspek tampilan, aspek penyajian dan aspek penggunaan. Uji validasi ahli materi menguji aspek kesesuai isi dan aspek kebahasaan. Dalam pengujian aplikasi oleh ahli media dan ahli materi memperoleh skor 93\% dan hasil uji respon siswa sekolah memperoleh skor 94\% dapat simpulkan bahwa aplikasi game edukasi "TANARA" sangat layak digunakan.
\end{abstract}

Kata kunci: budaya nusantara; game; MDLC; android; unity; corel draw; angket; TANARA.

\begin{abstract}
Educational game application about the culture of the archipelago "TANARA" was created as an alternative medium of learning to get to know the culture that exists in Indonesia for special children of school students. The methodology used in this research is the Multimedia Development Life Cycle $(M D L C)$ sourced from Luther collected by Sutopo, which consists of six concepts, designs, combined materials, testing and distribution. Educational game application "TANARA" is designed and created using Corel Draw software for design and unity for programming the final results of an Android-based application that is run offline. Validation testing application for media experts and material experts in the form of questionnaires. The validation test of media experts was carried out with aspects of appearance, presentation aspects and aspects of use. Test the validation of expert material content suitability aspects and linguistic aspects. In testing the application by media experts and expert material obtained a score of $93 \%$ and the response test results of students obtaining a score of $94 \%$ can be simplified with the educational game application "TANARA" very feasible to use.
\end{abstract}

Keywords: budaya nusantara; games; MDLC; android; unity; corel draw; questionnaire; TANARA. 


\section{PENDAHULUAN}

\subsection{Budaya}

Budaya merupakan warisan leluhur secara turun menurun, tindakan yang dilakukan dalam kehidupan sehari - hari. Kebudayaan adalah keseluruhan gagasan dan karya manusia, yang harus dibiasakan dengan belajar, beserta keseluruhan dari hasil budi karyanya itu [5]. Kebudayaan merupakan keseluruhan total dari apa yang pernah dihasilkan oleh mahluk manusia yang menguasai planet ini sejak jaman ia muncul di muka bumi kira-kira empat juta tahun yang lalu, sampai sekarang (perkiraan waktu munculnya manusia di muka bumi ini, adalah hasil analisa terbaru metode potassium-argon untuk mengukur umur lapisan lapisan bumi).

\subsection{Game}

Dalam melestarikan budaya Nusantara dan seiring perkembangan teknologi yang ada, terdapat beberapa cara untuk mengetahui dan melestarikan budaya yaitu melalui Game. Game berasal dari kata bahasa inggris yang memiliki arti dasar "Permainan" [1]. Permainan dalam hal ini merujuk pada pengertian "kelincahan intelektual" (intellectual playbility). Game juga bisa diartikan sebagai arena keputusan dan aksi pemainnya. Ada target - target dan misi untuk dapat dicapai pemainnya. Kelincahan intelektual, pada tingkat tertentu merupakan ukuran sejauh mana Game itu menarik untuk dimainkan secara maksimal.

\subsection{Unity}

Game edukasi tentang budaya nusantara ini dirancang menggunakan software Unity. Unity merupakan salah satu game engine yang banyak digunakan [3]. Unity menyediakan fitur pengembangan game dalam berbagai platform yaitu Web, Windows, Mac, Android, iOS, Xbox, Playstation 3 dan Wii. Unity mendukung pembuatan game 2D dan 3D, namun lebih ditekankan pada 3D. Bahasa pemograman yang digunakan pada Unity yaitu Bahasa pemograman JaveScript, C\# dan BooScript.

\subsection{Android}

Teknologi yang digunakan dalam pembuatan game edukasi tentang Budaya Nusantara yaitu berbasis Android, dimana mengikuti perkembangan teknologi saat ini alat telekomunikasi sudah berbasis Android. Android merupakan sebuah sistem operasi perangkat mobile berbasis linux yang mencakup sistem operasi, middleware, dan aplikasi [7]. Beberapa pengertian lain Android, yaitu:

1) Merupakan platorm terbuka (open source) bagi para pengembang (programmer) untuk membuat aplikasi.

2) Merupakan sistem operasi yang dibeli Google Inc. dari Android Inc.

3) Bukan bahasa pemograman, tetapi hanya menyediakan lingkungan hidup atau run time environment yang disebut DVM (Dalvik Virtual Machine) yang telah di oplimasi untuk alat/Device dengan sistem memori kecil. Android tersedia secara open source bagi manufaktur perangkat keras untuk memodifikasi sesuai kebutuhan.

\subsection{Multimedia}

Multimedia adalah beberapa kombinasi dari teks, gambar, suara, animasi dan video dikirim ke anda melalui komputer atau alat elektronik lainnya atau dengan manipulasi digital. Elemen - elemen pada multimedia secara umum yaitu [8]:

1) Teks, merupakan salah satu komponen multimedia yang sangat ampuh dan jelas dalam penyampaian informasi. Penggunaan teks misalnya digunakan pada judul menu, menu-menu, dan tombol. Teks dibagi menjadi dua tipe yaitu serif dan sans serif. Serif memiliki dekorasi kecil pada akhir setiap huruf dan paling sering digunakan untuk dokumen. Sedangkan sans serif sering digunakan pada tampilan komputer.

2) Gambar merupakan komponen multimedia yang dapat menyampaikan informasi lebih menarik. Gambar sangat berguna untuk menyampaikan informasi yang tidak dapat dijelaskan dengan kata-kata. Gambar yang dihasilkan oleh komputer terbagi menjadi dua, yaitu:

a. Bitmaps yaitu gambar yang terdiri dari titik-titik kecil yang membentuk sebuah gambar.

b. Vector-drawn yaitu gambar yang dihasilkan dari koordinat Cartesian yang biasanya menghasilkan bentuk garis, lingkaran, kotak, dan sebagainya.

3) Suara merupakan komponen yang paling mengena oleh panca indera manusia. Suara dapat memberikan kesenangan seperti dalam mendengarkan musik, atau dapat memberikan suasana yang dapat mengubah mood seseorang. 
a. Animasi merupakan komponen multimedia yang dapat membuat suatu gambar atau tulisan terlihat lebih hidup dengan menampilkan potongan - potongan gambar yang berganti - ganti secara cepat. Selain itu animasi juga dapat membuat slide presentasi menjadi lebih menarik. Contoh animasi seperti tweening, fade in, fade out, zoom in, zoom out dan sebagainya.

b. Video merupakan komponen multimedia yang terdiri dari gambar - gambar dan bergerak dengan sangat cepat secara berurutan. Video merupakan komponen paling menarik dalam multimedia dan video juga memiliki kekuatan untuk membawa pengguna komputer lebih dekat ke kehidupan nyata. Dengan menambahkan komponen video di dalam project dapat menyampaikan pesan dan memperkuat cerita. Selain itu orang-orang yang melihat video cenderung dapat mengingat lebih dari yang mereka lihat.

\subsection{Unified Modeling Language}

Unified Modeling Language (UML) Merupakan Perkembangan teknik pemograman berorietasi objek muncun standarisasi Bahasa pemodelan untuk pembangunan perangkat lunak yang dibangun menggunakan Teknik pemrograman berorientasi objek. ${ }^{[2]}$ Komputer UML muncul karena adanya kebutuhan pemodelan visual untuk menspesifikasikan, menggambarkan, membangun dan dokumentasi dari system pernagkat lunak. UML merupakan Bahasa visual untuk pemodelan dan komunikasi mengenai sebuah system dengan menggunakan diagram dan teks - teks pendukung.

\subsection{Corel Draw x6}

Corel Draw adalah sebuah program komputer yang melakukan editing pada garis vector [2]. Program ini dibuat oleh Corel, sebuah perusahaan software yang berkantor di Ottawa, Kanada. Corel draw memiliki kegunaan untuk mengolah gambar, oleh karena itu banyak digunakan pada pekerjaan dalam bidang publikasi atau percetakaan ataupun pekerjaan di bidang lain yang membutuhkan proses visualisasi.

\subsection{Skala Likert}

Skala Likert Modifikasi yaitu untuk menghilangkan kelemahan yang terkandung oleh skala lima tingkat, dengan alasan yang dikemukakan seperti di bawah ini[4]:

1) Kategori Undeciden itu mempunyai arti ganda, bisa diartikan belum dapat memutuskan atau memberi jawaban (menurut konsep aslinya), bisa juga diartikan netral, setuju tidak, tidak setuju pun tidak, atau bahkan ragu - ragu. Kategori jawaban ganda arti (multi interpretable) ini tentu saja tidak diharapkan dalam suatu instrument.

2) Tersedianya jawaban yang ditengah itu menimbulkan jawaban ke tengah (central tendency effect), terutama bagi mereka yang ragu - ragu atas arah kecenderungan pendapat responden, kea rah setuju atau kearah tidak setuju. Jika disediakan kategori jawaban itu akan menghilangkan banyak data penelitian sehingga mengurangi banyaknya informasi yang dapat dijaring para responden.

\subsection{Storyboard}

Storyboard adalah visualisasi ide dari aplikasi yang akan dibangun, sehingga dapat memberikan gambaran dari aplikasi yang akan dihasilkan [6]. Storyboard dapat dikatakan juga visual script yang akan dijaikan outline dari sebuah proyek, ditampilkan shot by shot yang biasa disebut dengan istilah scene. Storyboard sekarang lebih banyak digunakan untuk membuat kerangka pembuatan website dan proyek media interaktif lainnya seperti iklan, filem pendek, game, dan media pembelajaran interaktif ketika dalam tahap perancangan atau desain.

\section{METODOLOGI PENELITIAN}

Model Pengembangan Multimedia Development Life Cycle digunkan untuk megembangkan media pembelajaran agar lebih menarik. MDLC dikembangkan menggunakan teknologi Arguemented Reality berbasis Android/Ios sesuai dengan perkembangan saat ini. Multimedia Development Life Cycle ${ }^{[6]}$ yang bersumber dari Luther dan sudah dimodifikasi oleh Sutopo metodologi pengembangan Multimedia Development Life Cycle terdiri dari enam tahap yaitu konsep (consept), desain (design), pengumpulan materi (material collecting), pembuatan (assembly), pengujian (testing) dan distribusi (distribution). Keenam tahap ini tidak harus berurutan dalam praktiknya, tahap - tahap tersebut dapat saling bertukar posisi. Meskipun begitu, tahap konsep memang harus menjadi hal yang pertama kali dikerjakan. 


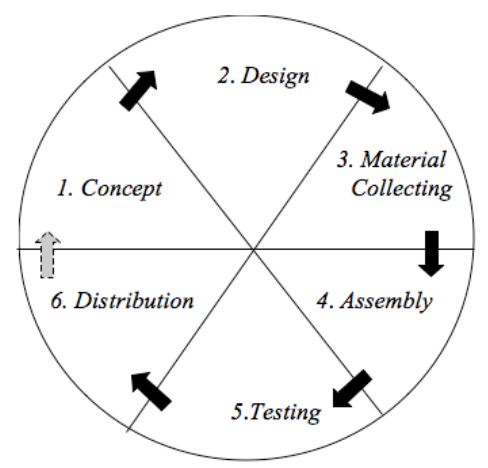

Gambar 1. Metodologi Pengembangan Multimedia

\subsection{Concept}

Konsep merupakan langkah awal dalam membuat sebuah aplikasi karena konsep menentukan tujuan dan sasaran pengguna aplikasi.

\subsection{Design}

Desain merupakan rancangan atau gambaran yang sebuah aplikasi mulai dari bentuk aplikasi, jenis aplikasi, kebutuhan, tampilan.

\subsection{Material Collecting}

Kebutuhan Alat merupakan tahap penentuan apa saja yang digunakan dalam proses pembuatan aplikasi.

\subsection{Assembly}

Proses pembuatan aplikasi merupakan langkah penyatuan seluruh elemen mulai dari konsep, desain dan kebutuhan alat terdiri atas storyboard dan diagram alur.

\subsection{Testing}

Tahap pengujian merupakan tahap uji coba aplikasi untuk menilai aplikasi terdapat kesalahan atau tidak.

\subsection{Distribution}

Distribusi proses akhir dalam pebuatan aplikasi dan sebagai tahap evaluasi pengembangan aplikasi selanjutnya.

\section{HASIL DAN PEMBAHASAN}

\subsection{Hasil Pembuatan Aplikasi Game Edukasi “TANARA"}

Penelitian ini adalah jenis penelitian yang menerapakan produk berupa aplikasi game edukasi pengenalan budaya nusantara. Gambaran umum dari system yang di buat adalah merancang sebuah aplikasi game edukasi dengan menggunakan basis android yang dapat digunakan sebagai sarana belajar untuk mengenal budaya yang ada di Indonesia.

\section{1) Konsep}

Penulis akan menjelaskan gambaran tentang Game ini secara garis besar:

a. Game ini membahas mengenai budaya nusantara. Pengenalan tari Adat dari setiap daerah, pakaian adat yang dikenakan oleh masyarakat daerah dan jenis rumah adat yang ada di Indonesia.

b. Game edukasi ini bergenre Game tebak gambar. Game dimainkan oleh satu user

c. Ada skor yang akan diperoleh user jika memainkan Game. Skor dalam bentuk poin. Jika menjawab dengan benar akan mendapat 10 poin jika salah maka tidak dapat poin. 
Tabel 1. Konsep desain

\begin{tabular}{cc}
\hline Konsep & Keterangan \\
\hline Judul & Game Edukasi Tentang Budaya Nusantara \\
& "TANARA" \\
Genre & Tebak Gambar \\
Pengguna & Anak Sekolah dan umum \\
Audio & Intrumen lagu daerah nusantara \\
Interaktivitas & Pause, continue, skip dan move \\
Hasil & Mendapatkan skor jika menyelesaikan permainan. \\
\hline
\end{tabular}

2) Desain

Aplikasi Game edukasi "TANARA" dimainkan oleh satu user. User berfungsi untuk mendeskripsikan peran pemain dalam permainan ini. Proses desain perancanaan dan pembuatan Game edukasi "TANARA" digambarkan melalui Storyboard, Flowchart, Unified Modeling Language (UML). Diagram UML yang digunakan dalam perancangan system yaitu Use Case Diagram, Activity Diagram dan Contexs Diagram.

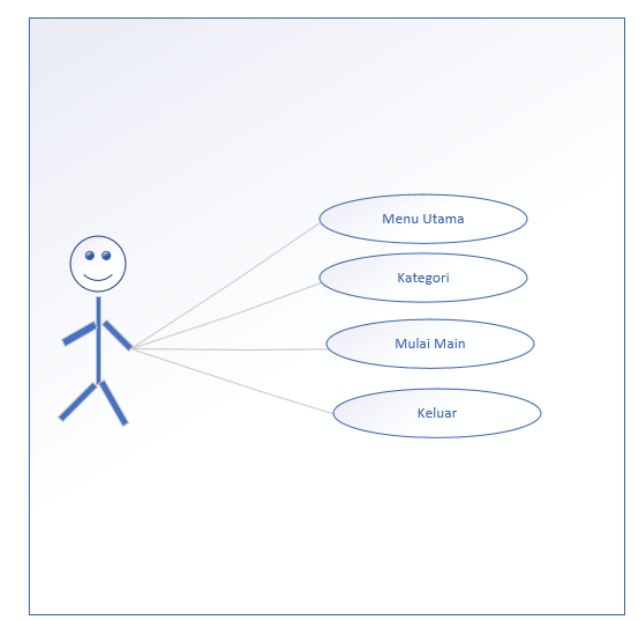

\section{Gambar 2. Use Case Diagram Aplikasi}

3) Storyboard

Storyboard merupakan gambaran scenario yang dibuat secara bertahap yaitu setiap scene yang disusun menerangkan materi game yang dibuat.

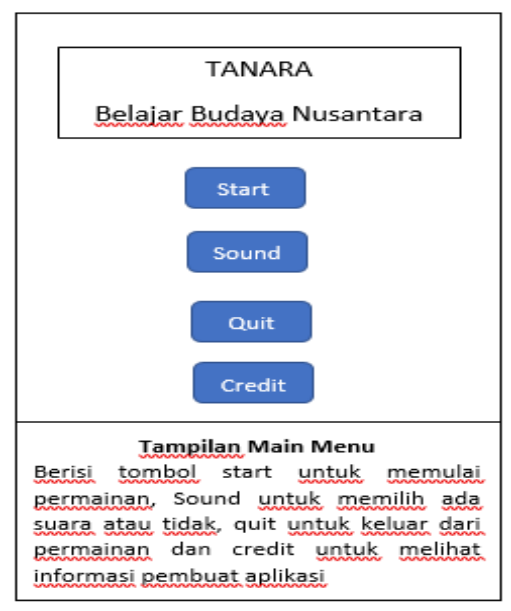

Gambar 3. Tampilan Menu Utama

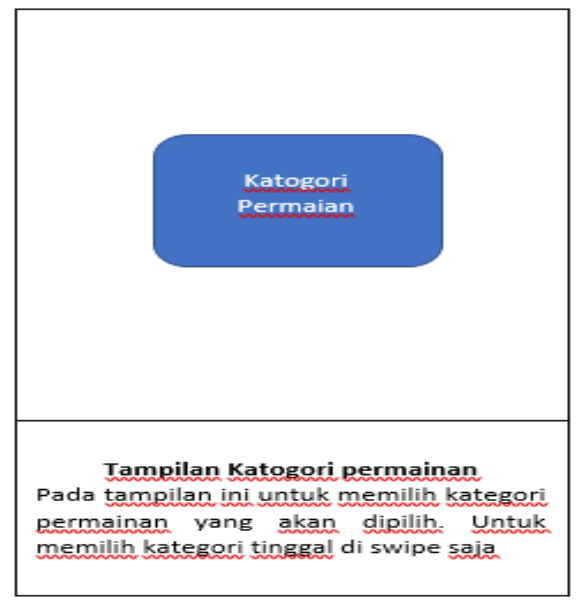

Gambar 4. Tampilan Pemilihan Kategori 


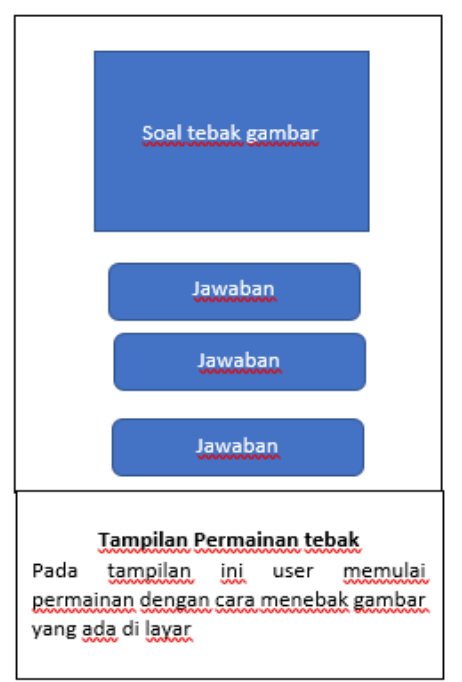

Gambar 5. Tampilan Menu Permainan

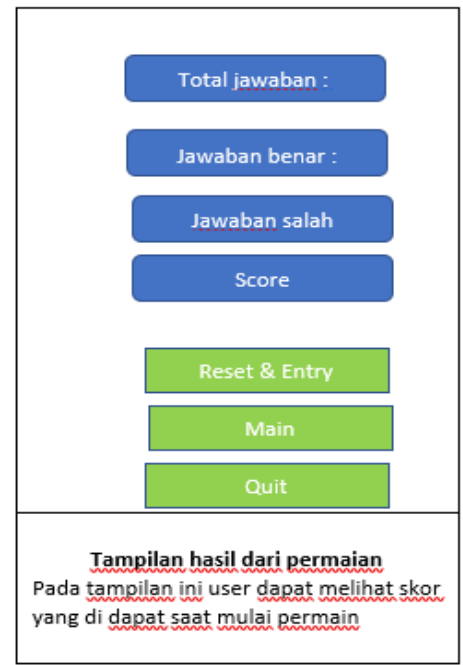

Gambar 6. Tampilan Hasil Akhir Permainan

Berikut hasil akhir pembuatan aplikasi game edukasi budaya nusantara:

1) Halaman Pembukan Unity, menunjukan bahwa game ini di buat menggunakan software Unity.

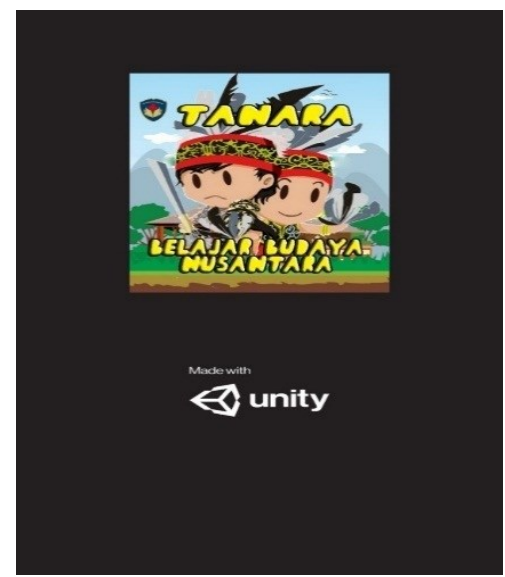

Gambar 7. Loading made in Unity

2) Halaman menu utama aplikasi game, menampilkan seluruh menu pokok yang ada di dalam aplikasi game edukasi "TANARA". Menu utama berisi tombol main, informasi, budaya dan pengaturan suara.

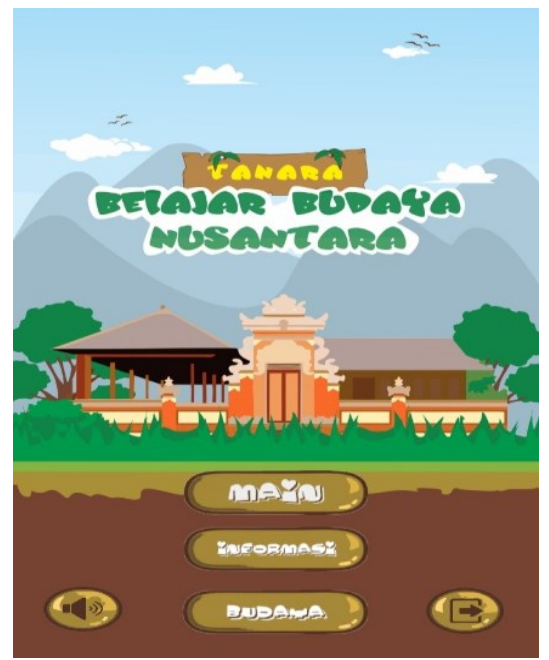

Gambar 8. Tampilan Menu Utama Aplikasi 
3) Halaman menu informasi, merupakan halaman untuk menampilkan informasi tentang aplikasi game edukasi dan pembuat aplikasi.

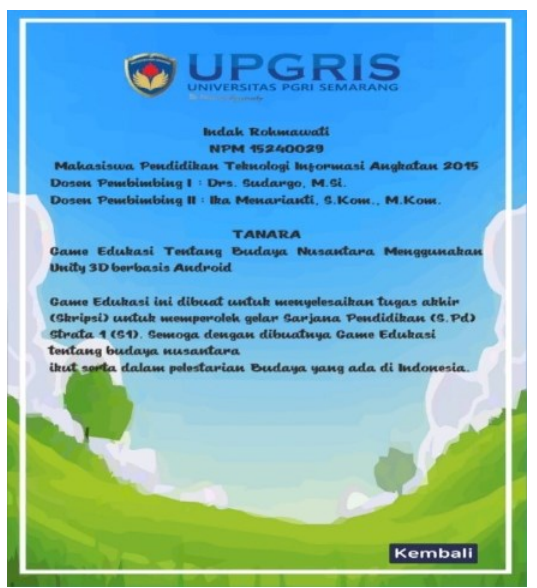

Gambar 9. Menu Informasi

4) Halaman menu Budaya, merupakan halaman yang berisi informasi mengenai jenis budaya yaitu pakaian adat, rumah adat dan tari adat. Budaya digunakan untuk belajar terlebih dahulu sebelum bermain.

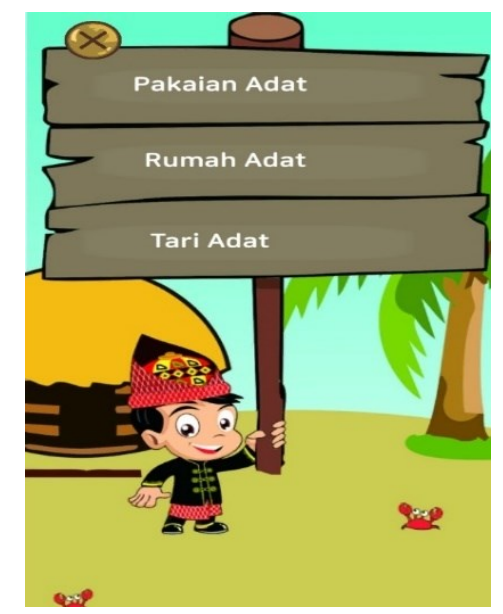

Gambar 10. Menu Budaya

5) Halaman sub menu Budaya pakaian adat, merupakan halaman yang berisi nama dan daerah asal pakaian adat ada di Indonesia

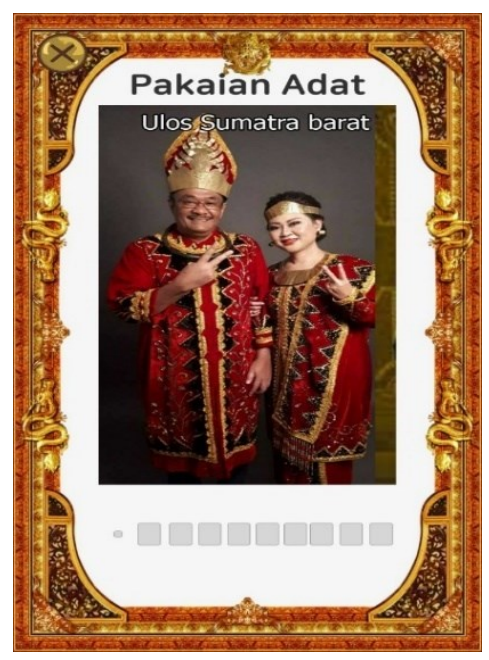

Gambar 11. Sub Menu Pakaian Adat 
6) Halaman sub menu Budaya rumah adat, merupakan halaman yang berisi nama dan daerah asal pakaian adat ada di Indonesia

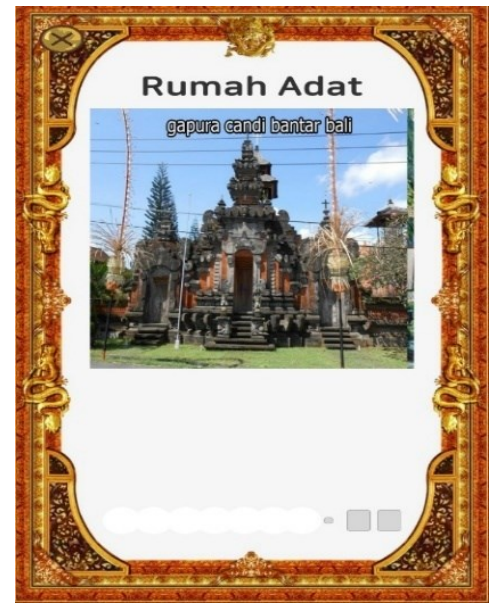

\section{Gambar 12. Sub Menu Rumah Adat}

7) Halaman sub menu Budaya tari adat, merupakan halaman yang berisi nama dan daerah asal pakaian adat ada di Indonesia

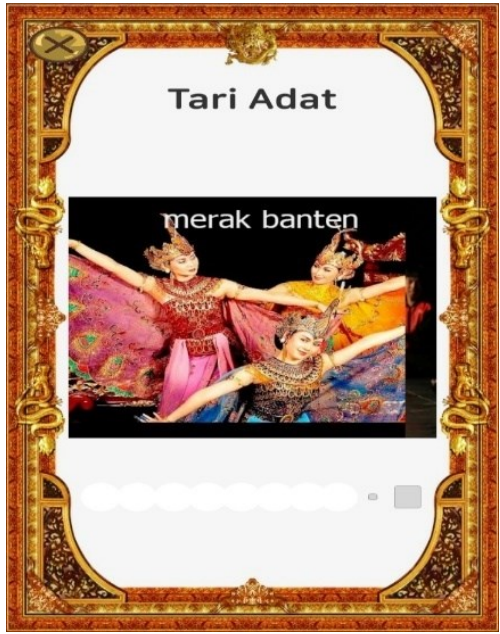

\section{Gambar 13. Sub Menu Tari Adat}

8) Halaman menu main, merupakan halaman untuk mulai bermain tebak gambar. Kuis ini merupakan penguasaan materi untuk mengetahui tingkat pengetahuan user mengenai budaya khususnya untuk pakaian adat, rumah adat dan tari adat.

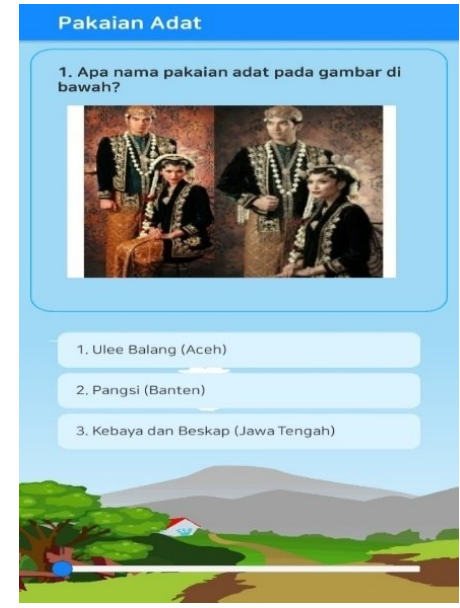

Gambar 14. Halaman Mulai Bermain Kategori Pakaian Adat 


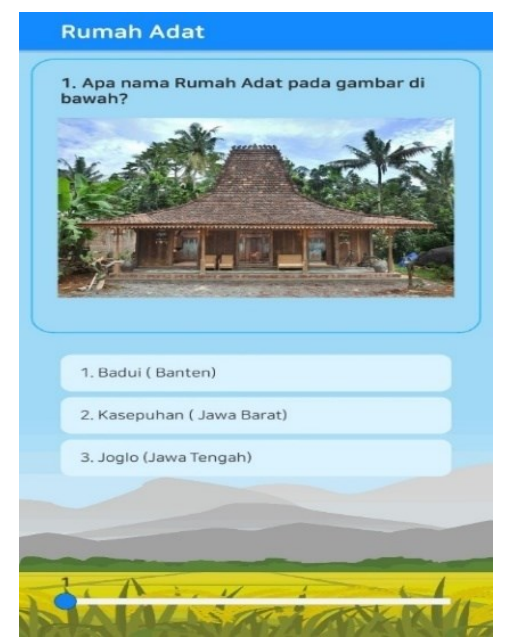

Gambar 15. Halaman Mulai Bermain Kategori Rumah Adat

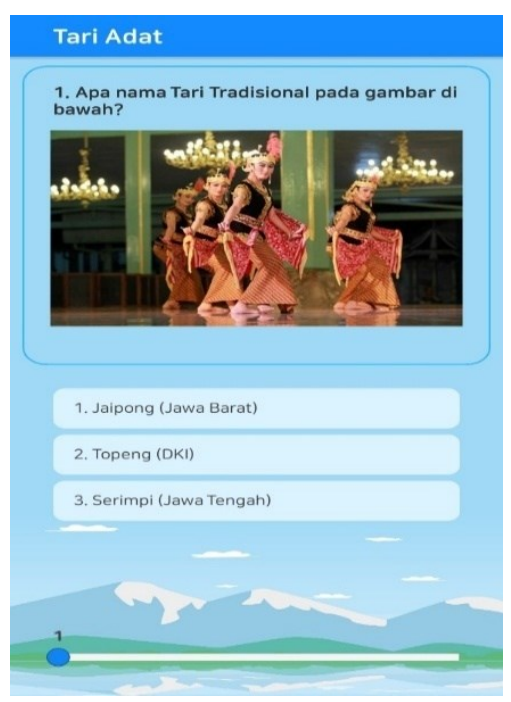

\section{Gambar 16. Halaman Mulai Bermain Kategori Tari Adat}

9) Halaman hasil, berisi informasi hasil nilai saat bermain. Jika menebak gambar dengan benar akan mendapat nilai 10 dan jika salah maka tidak dapat nilai.

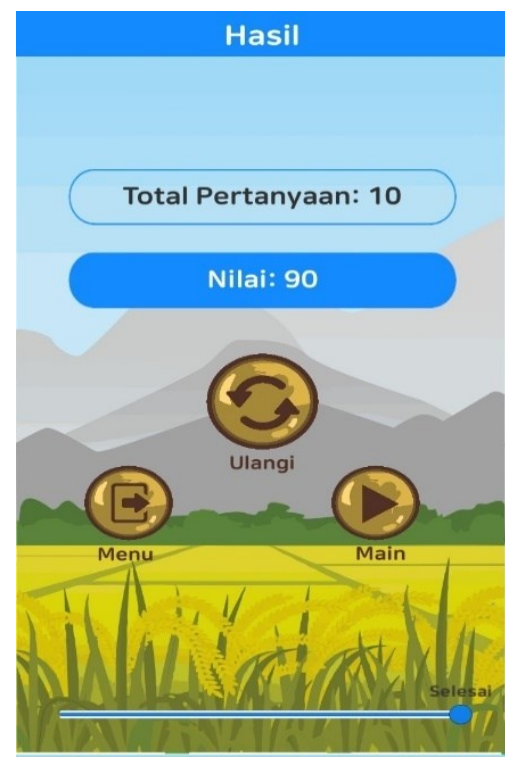

Gambar 12. Hasil Bermain 


\subsection{Pengujian Aplikasi Game}

Pengujian aplikasi game edukasi "TANARA" yang telah di buat penelitian ini dilakukan dengan menggunakan blackbox dan angket. Tahap pengujian blackbox dilakukan untuk menguji rangkain tombol dan fungsi yang terdapat dalam aplikasi. Pengujian dijalankan pada smartphone dengan sistem android Lolipop. Pengujian dilakukan dengan cara mengekesekusi souce code. Berikut tabel hasil pengujian menggunakan blackbox ditunjukan pada tabel 2 .

Tabel 2. Hasil pengujian blackbox

\begin{tabular}{|c|c|c|c|}
\hline Nama Pengujian & Bentuk Pengujian & Hasil yang diharapkan & Hasil Pengujian \\
\hline Loading & Membuka Aplikasi & $\begin{array}{l}\text { Tampilan Icon Unity dan } \\
\text { Icon TANARA }\end{array}$ & Berhasil \\
\hline Pengujian Menu Main & Menyentuh tombol mulai & $\begin{array}{l}\text { Masuk ke menu kategori } \\
\text { permainan }\end{array}$ & Berhasil \\
\hline $\begin{array}{l}\text { Pengujian menu kategori } \\
\text { permainan rumah adat }\end{array}$ & $\begin{array}{l}\text { Menyentuh tombol } \\
\text { rumah adat }\end{array}$ & $\begin{array}{l}\text { Masuk kepermainan } \\
\text { kategori rumah adat }\end{array}$ & Berhasil \\
\hline $\begin{array}{l}\text { Pengujian menu kategori } \\
\text { permainan Pakaian adat }\end{array}$ & $\begin{array}{l}\text { Menyentuh tombol } \\
\text { Pakaian adat }\end{array}$ & $\begin{array}{l}\text { Masuk kepermainan } \\
\text { kategori Pakaian adat }\end{array}$ & Berhasil \\
\hline $\begin{array}{l}\text { Pengujian menu kategori } \\
\text { Tari adat }\end{array}$ & $\begin{array}{l}\text { Menyentuh tombol Tari } \\
\text { adat }\end{array}$ & $\begin{array}{l}\text { Masuk kepermainan } \\
\text { kategori tari adat }\end{array}$ & Berhasil \\
\hline $\begin{array}{l}\text { Pengujian menu } \\
\text { informasi }\end{array}$ & $\begin{array}{l}\text { Menyentuh tombol } \\
\text { informasi }\end{array}$ & $\begin{array}{l}\text { Menampilkan biografi } \\
\text { pembuat aplikasi }\end{array}$ & Berhasil \\
\hline Pengujian tombol ulangi & Menyentuh tombol mulai & $\begin{array}{l}\text { Mengulangi permaian } \\
\text { sesuai kategori awal }\end{array}$ & Berhasil \\
\hline Pengujian tombol menu & Menyentuh tombol menu & Kembali ke menu utama & Berhasil \\
\hline Pengujian tombol keluar & $\begin{array}{l}\text { Menyentuh tombol } \\
\text { keluar }\end{array}$ & $\begin{array}{l}\text { Keluar dari aplikasi } \\
\text { permainan }\end{array}$ & berhasil \\
\hline
\end{tabular}

Tahapan pengujian menggunakan angket dilakukan oleh validator ahli media dan ahli materi. Pengujian ini dilakukan menilai berdasrkan aspek - aspek. Uji validitas ahli media menilai berdasarkan aspek tampilan, aspek penyajian dan aspek penggunaan. Uji validitas ahli media berdasarkan aspek kesesuain isi materi dan aspek kebahasaan. Uji coba produk diberikan kepada siswa lima untuk menguji penggunaan aplikasi. Dalam pelaksanaannya aplikasi ini dijalankan oleh masing - masing pengguna yang digunakan untuk mendapatkan data responden tentang penilaian aplikasi yang telah dibuat.

Setiap responden akan diberi angket, kemudian diisi dengan jawaban Sangat Setuju, Setuju,setuju,tidak setuju dan sangat tidak setuju. Untuk mencari nilai presentase dari masing - masing jawaban angket menggunkan rumus skala Likert. Berdasarkan penilaian terhadap aspek kemudian dilakukan perhitungan keseluruhan dengan rumus sebagai berikut:

$$
\text { Presentase tiap aspek }=\frac{\text { jumlah skor aspek }}{\text { Jumlah } \text { kriteria aspek } \times \text { bobot tertinggi }} \times 100 \%
$$

Berikut tabel uji validitas yang dilakukan oleh validator ahli media.

Tabel 2. Tabel kriteria

\begin{tabular}{ccc}
\hline No & Nilai Presentase & Kriteria \\
\hline 1 & $81 \%-100 \%$ & Sangat Layak \\
2 & $61 \%-80 \%$ & Layak \\
3 & $41 \%-60 \%$ & Cukup Layak \\
4 & $21 \%-40 \%$ & Kurang Layak \\
5. & $0 \%-20 \%$ & Tidak Layak \\
\hline
\end{tabular}

Tabel 3. Tabel pengujian ahli media

\begin{tabular}{cccccc}
\hline \multirow{2}{*}{ No. } & \multirow{2}{*}{ Aspek } & \multicolumn{2}{c}{ Skor } & \multirow{2}{*}{ Jumlah } & $\begin{array}{c}\text { Skor } \\
\text { maksimal }\end{array}$ \\
\cline { 3 - 4 } & & $\boldsymbol{V 1}$ & $\boldsymbol{V} \mathbf{2}$ & & 48 \\
1. & Aspek Tampilan & 20 & 20 & 40 & 16 \\
2. & Aspek Penyajian & 8 & 7 & 15 & 16 \\
3. & Aspek Penggunaan & 8 & 8 & 16 & 80 \\
\hline & Jumlah & 36 & 35 & 71 & \\
\hline
\end{tabular}




$$
\begin{aligned}
\text { Presentase Kelayakan } & =\frac{71}{80} \times 100 \% \\
& =0,88 \times 100 \% \\
& =88 \%
\end{aligned}
$$

Berdasarkan hasil penilaian oleh ahli media, game edukasi "TANARA" memperoleh presentase tingkat pencapaian $88 \%$ dan berada pada kualifikasi sangat layak digunakan, maka dengan demikian dapat disimpulkan

\begin{tabular}{|c|c|c|c|c|c|}
\hline \multirow{2}{*}{ No. } & \multirow{2}{*}{ Aspek } & \multicolumn{2}{|c|}{ Skor } & \multirow{2}{*}{ Jumlah } & \multirow{2}{*}{$\begin{array}{c}\text { Skor } \\
\text { maksimal }\end{array}$} \\
\hline & & $V 1$ & $V 2$ & & \\
\hline 1. & $\begin{array}{ll}\text { Aspek } & \text { Kesesuaian } \\
\text { Materi } & \end{array}$ & 20 & 18 & 38 & 40 \\
\hline 2. & $\begin{array}{l}\text { Aspek Kebahasaan } \\
\text { Jumlah }\end{array}$ & $\begin{array}{l}11 \\
31\end{array}$ & $\begin{array}{l}11 \\
29\end{array}$ & $\begin{array}{l}22 \\
60\end{array}$ & $\begin{array}{l}24 \\
64\end{array}$ \\
\hline
\end{tabular}
bahwa aplikasi ini valid dan layak digunakan. Berikut tabel uji validitas yang dilakukan oleh validator ahli materi.

Tabel 4 pengujian ahli materi

$$
\begin{aligned}
\text { Presentase kelayakan } & =\frac{60}{64} \times 100 \% \\
& =0,93 \times 100 \% \\
& =93 \%
\end{aligned}
$$

\begin{tabular}{|c|c|c|c|}
\hline \multicolumn{3}{|c|}{ Nomor } & \multirow{2}{*}{ Nama Siswa } \\
\hline URUT & NIPD & NISN & \\
\hline 1 & 1624 & 0092283475 & Ajeng Alisca Lolita Rose \\
\hline 2 & 1627 & 0087812534 & Andika Dwi Darmawan \\
\hline 3 & 1628 & 0095632045 & Arga Akbar Pamungkas \\
\hline 4 & 1603 & 0089704170 & Arga Mukti Darma Putra \\
\hline 5 & 1629 & 0086668811 & Arya Ragil Pamungkas \\
\hline 6 & 1630 & 0074391072 & Arya Reihan Agathan \\
\hline 7 & 1631 & 0099654337 & Aulia Diva Anggita \\
\hline 8 & 1633 & 0084070437 & Bima Setiawan \\
\hline 9 & 1634 & 0082718435 & Daffa Rafy Ardian \\
\hline 10 & 1635 & 0085759958 & Deco Ahmat Cesar \\
\hline 11 & 1636 & 0083638443 & Dhimas Nur Cahya \\
\hline 12 & 1637 & 0088463350 & Elvina Putri \\
\hline 13 & 1638 & 0085750054 & Fahmi Ilham Rifaliano \\
\hline 14 & 1639 & 0088643932 & Hakan Syukur Setiawan \\
\hline 15 & 1608 & 0066333014 & Imannuel Fernando Nur Cristian \\
\hline 16 & 1640 & 0091591913 & Lutfi Ardiansyah Putra \\
\hline 17 & 1676 & 0093244633 & Nabila Rafa Nugroho \\
\hline 18 & 1644 & 0087370157 & Rafael Dwi Pradita \\
\hline 19 & 1645 & 0085866854 & Rangga Dwi Kurniawan \\
\hline 20 & 1647 & 0083555871 & Rehan Kurniawan \\
\hline 21 & 1648 & 0088168640 & Reni Fitria Dewi \\
\hline 22 & 1649 & 0087131395 & Reta Akalina Vernanda \\
\hline 23 & 1650 & 0081781149 & Reva Aulia Vernanda \\
\hline 24 & 1652 & 0085616104 & Suci Rahmawati \\
\hline 25 & 1653 & 0093031677 & Tirto Adi Nugroho \\
\hline 26 & 1654 & 0092474683 & Villa Putri Rahmat Wati \\
\hline 27 & 1655 & 0082400467 & Zidan Fatkhurahman \\
\hline
\end{tabular}

Berdasarkan hasil penilaian oleh ahli materi, game edukasi "TANARA" memperoleh presentase tingkat pencapaian 93\% dan berada pada kualifikasi sangat layak digunakan, maka dengan demikian dapat disimpulkan bahwa aplikasi ini valid dan layak digunakan. Berikut tabel uji coba produk oleh siswa SD kelas lima.

Tabel 5. Uji coba produk

Presentase kelayakan $=\frac{1224}{1296} \times 100 \%$

$$
\begin{aligned}
& =0,94 \times 100 \% \\
& =94 \%
\end{aligned}
$$


Berdasarkan hasil pengujian yang dilakukan kepada responden siswa kelas lima Sekolah dasar dapat disimpulkan bahwa secara keseluruhan penilaian game edukasi "TANARA" memperoleh hasil dari semua aspek memenuhi praktikalitas dengan memperoleh skor 94\% yang berada pada kategori sangat layak digunakan dan praktis digunakan.

\subsection{Distribusi}

Tahap distribusi game edukasi budaya nusantara "Tanara" dilakukan dengan mengupload file *.apk ke web program studi Pendidikan Teknologi Informasi.

\section{KESIMPULAN}

\subsection{Kesimpulan}

Berdasarkan latar belakang rumusan masalah dan batasan masalah dapat disimpulkan bahwa aplikasi game edukasi "TANARA" telah didapat hasil sebagai berikut:

1) Game edukasi "TANARA" dirancang dengan metode pengembangan Multimedia Development Life Cycle (MDLC) melalui enam tahap yaitu konsep, desain, pengumpulan materi, pembuatan, pengujian dan distribusi

2) Aplikasi game edukasi tentang budaya nusantara "TANARA" bebasis android menggunakan unity 3D. Dirancang dan dibuat menggunakan software corel draw untuk desain dan unity untuk pemograman. Aplikasi game edukasi "TANARA" telah memenuhi kriteria ke validan dan kepraktisan sehingga layak digunakan sebagai media bantu untuk belajar pengenalan budaya nusantara.

3) Hasil perhitungan uji aplikasi menggunakan du acara yaitu metode black-box dan menggunakan anket. Metode black-box menunjukan bahwa permaian sudah berjalan sesuai dengan konsep dan kebutuhan. Hal itu ditunjukan pada tabel 2 yang menunjukan seluruh pengujian dinyatakan "Berhasil" pada setiap fungsi aplikasi dan tombol. Berdasarkan uji validitas yang dilakukan oleh dua orang ahli materi dan media memperoleh skor $88 \%$ dapat simpulkan bahwa aplikasi game edukasi "TANARA" sudah tergolong aplikasi sangat valid dan layak untuk digunkan. Hasil perhitungan uji praktikalitas yang diujicobakan kepada siswa kelas 5 SD N 2 Bugangan memperoleh skor 94\% dapat disimpulkan bahwa aplikasi game edukasi "TANARA" sudah tergolong sangat praktis untuk digunakan oleh siswa maupun kalayak umum.

\subsection{Saran}

Dalam perancangan aplikasi game edukasi “TANARA” ini tentunya masih terdapat banyak kekurangan yang perlu dikaji dan dikembangkan lagi agar aplikasi game edukasi yang sempurna. Adapun saran yang diterapkan yaitu penambahan bank soal dan teknik acak dalam pemilihan soal agar pengguna tidak menggunakan aplikasi dengan basis ingatan serta penambahan animasi agar lebih menarik.

\section{DAFTAR PUSTAKA}

[1] Asmiatun, Siti. Astrid Novita Putri. 2017. Belajar membuat Game 2D dan 3D menggunakan unity. Cv Budi utama. Yogyakarta.

[2] Defrianto, Dony, Rinta Kridalukmana, Ike Pertiwi Windasari..2015. Pengembangan Permainan Edukatif Ragam BudayaNusantara Berbasis Android. Jurnal Teknologi dan Sistem Komputer. Vol.3 No.3 Agustus eISSN: 2338-0403.(https://jtsiskom.undip.ac.id/index.php/jtsiskom/article/view/12111/11763 diakses pada 26 Juli 2019)

[3] Dewi, Ade Riyantika, R.Rizal Isnanto, Kurniawan Teguh Martono.2015. Aplikasi Multimedia sebagai Media Pembelajaran Ilmu Pengetahuan Sosial Materi Budaya di Indonesia Menggunakan Unity Engine untuk Sekolah Dasar. Jurnal Teknologi dan Sistem Komputer. Vol.3 No.4 Agustus e-ISSN: 2338-0403. (https://jtsiskom.undip.ac.id/index.php/jtsiskom/article/download/12667/12286 diakses pada 28 Juli 2019)

[4] Hadi, Sutrisno. 1991. Analisis Butir untuk Instrumen Angket, Tes, dan Skala Nilai. Yogyakarta: FP UGM.

[5] Koentjaraningrat. 1969. Pengantar Antropologi. Jakarta: P. D Aksara.

[6] Maulana, Yusep. 2018. Junius Membuat Mobile Edukasi Android. Garut:CV Mobidu Sinergi.

[7] Supardi,Yuniar., Semua bisa jadi menjadi Programmer Android, Jakarta, PT Elex Media Komputindo, 2014.

[8] Vaughan, T. (2011). Multimedia: Making It Work 8th Edition. New York: McGraw-Hill. 